\title{
Sobre palheiros, agulhas, doutores e o conhecimento médico: o estilo de pensamento dos clínicos
}

\author{
On haystacks, needles, doctors, and medical \\ knowledge: the thought style of physicians
}

Kenneth R. de Camargo Jr. 1

\footnotetext{
1 Departamento de Planejamento e Administração de Saúde, Instituto de Medicina Social, Universidade do Estado do Rio de Janeiro. Rua São Francisco Xavier 524, Rio de Janeiro, $R J$ 20559-900, Brasil. kenneth@uerj.br
}

\begin{abstract}
This paper, the second in a series, reports on a study designed to assess how physicians operate selective mechanisms to sort out relevant and/or reliable information from what is presented to them. Twenty-four professors of internal medicine from two leading medical schools in Rio de Janeiro, Brazil, answered open-ended interviews. The conceptual framework adopted is based on Ludwik Fleck's work (on thought style). The thought style that emerged from this set of interviews can be briefly characterized as a largely intuitive, pragmatic, results-oriented search for relevant (i.e., potentially useful in practice) information, selected from sources with sufficient academic credibility and submitted to a primacy of practical knowledge. However, despite this skepticism, doctors lack resources (i.e. time, as well as knowledge of technical aspects of research, particularly in terms of epidemiology and statistics) to effectively assess the knowledge that is constantly being force-fed to them.
\end{abstract}

Key words Medical Anthropology; Medical Knowledge; Thought Style

Resumo Este artigo, o segundo de uma série, apresenta um estudo desenhado para avaliar como os médicos operam mecanismos para selecionar a informação relevante elou confiável dentre o que lhes é apresentado. Vinte e quatro professores de clínica médica de duas faculdades de Medicina relevantes no Rio de Janeiro foram submetidos a entrevistas abertas. O referencial conceitual adotado é baseado no trabalho de Ludwik Fleck (estilo de pensamento). O modo de pensar que emerge deste conjunto de entrevistas pode ser caracterizado resumidamente como uma busca amplamente intuitiva, pragmática, orientada a resultados, por informação relevante (isto é, potencialmente útil na prática), selecionada de fontes com suficiente credibilidade acadêmica e submetida a um primado do conhecimento prático. Apesar deste ceticismo, entretanto, os médicos carecem de recursos (isto é, tempo, conhecimento de aspectos técnicos da pesquisa, particularmente em termos de epidemiologia e estatística) para avaliar o conhecimento que os está continuamente alimentando à força.

Palavras-chave Antropologia Médica; Conhecimento Médico; Estilo de Pensamento 


\section{Introdução}

Referências à importância do conhecimento para a prática médica são ubíquas na literatura especializada. Um dos mais influentes manuais de clínica (Harrison's Principles of Internal Medicine - Isselbacher et al., 1994), tem nas suas páginas de abertura uma nota de advertência, encorajando os leitores a confirmar as informações nele contidas com outras fontes, que se inicia com a seguinte frase: "A medicina é uma ciência em permanente mudança”. De modo ainda mais explícito, um manual de Medicina Baseada em Evidências (MBE) justifica a necessidade da MBE com o seguinte argumento, entre outros: “(...) novos tipos de evidência estão sendo geradas agora que, quando as conhecemos e compreendemos, geram mudanças freqüentes, significativas, no modo de tratarmos de nossos pacientes" (Sackett et al., 1997:5).

Considerando as concepções presentes nestes textos, ou seja, que: (a) a prática médica é ao menos influenciada, se não determinada, pelo conhecimento ("ciência", "evidência”) e (b) tal conhecimento muda substancialmente ao longo do tempo, segue-se que ter critérios para selecionar e absorver o conhecimento relevante é estrategicamente importante para os médicos. Este artigo é o segundo relato de um estudo exploratório e qualitativo, tentando caracterizar tais critérios e seu processo de aplicação.

\section{Referencial conceitual}

A referência teórica central deste texto é a epistemologia comparativa de Ludwik Fleck (1979). As próximas linhas apresentarão um esboço breve de seus desdobramentos teóricos - para uma exposição detalhada, ver Fleck (1979) e Cohen \& Schnelle (1986); sobre a atualidade e importância de Fleck, ver Hacking (1999) e Kuhn $(1979,1996)$.

Dois conceitos são centrais em Fleck: o coletivo de pensamento (Denkkollektiv) e ao estilo de pensamento (Denkstil). O primeiro é definido como “(...) uma comunidade de pessoas intercambiando idéias mutuamente ou mantendo interação intelectual; também veremos por implicação que esta também provê o 'suporte' especial para o desenvolvimento histórico de qualquer campo do pensamento, bem como do nível de cultura e conhecimento dados" (Fleck, 1979:39) e o segundo como “(...) uma constrição definida do pensamento, e até mais; (...) a totalidade da preparação ou disponibilidade intelectuais para uma forma particular de ver e agir ao invés de qualquer outra"
(Fleck, 1979:64). Note-se que o estilo de pensamento não é uma característica opcional que pode ser voluntariamente adotada, mas antes uma imposição feita pelo processo de socialização representado pela inclusão em um coletivo de pensamento.

Fleck (1979) distingue duas áreas de importância no interior de um coletivo de pensamento na ciência moderna: uma compreendendo os experts que efetivamente produzem conhecimento, por ele chamada de "círculo esotérico" (ele ainda detalha mais esta região, descrevendo o círculo mais interno de experts especializados e o círculo externo de experts generalistas), e a outra constituída pelos "leigos educados”, o "círculo exotérico”. Esta topografia permite a distinção entre formas diferentes de comunicação; a ciência dos experts é caracterizada pelo periódico técnico/científico e pelo livro de referência, o primeiro representando o diálogo intenso, fragmentado, pessoal e crítico dentro de um campo dado do conhecimento, e o segundo a organização sinóptica deste; o círculo exotérico é alimentado pelos periódicos de ciência popular ou de divulgação, que são uma “(...) exposição artisticamente atraente, vívida e legível (...) com uma atribuição de valores apodíctica para simplesmente aceitar ou rejeitar um dado ponto de vista" (Fleck, 1979: 112). Finalmente, a introdução ao círculo exotérico - comparada por Fleck a um ritual de iniciação - é baseada num quarto tipo de meio textual científico, o manual básico.

Estes elementos permitem a construção da geografia de um campo intelectual, descrevendo não apenas pessoas e lugares, mas as trocas que ocorrem entre eles. Note-se que eu não pretendo atribuir a estes objetos mais valor do que o de uma notação conveniente - transformar o modelo de Fleck num relato ontologicamente fundado seria ir contra a própria lógica de suas idéias.

As instituições médicas (incluindo a saúde pública, a assistência à saúde e as escolas médicas), o conhecimento e prática médicos são permeados por um estilo de pensamento específico (Fleck, 1986). Isto não significa que esta seja uma região homogênea. Isto é ainda mais complicado na Medicina, uma vez que o seu eixo principal não é a produção de conhecimento, mas a sua aplicação numa variedade de situações de acordo com princípios éticos (Canguilhem, 1978); embora uma descrição do que poderia ser chamado de um estilo de pensamento médico possa ser esboçada (ver por exemplo - Bates, 2000; Fleck, 1986; Luz \& Camargo Jr., 1997), isto não deve ofuscar as diferenças extremas no interior deste campo. 
Giddens (1990) descreveu como leigos confiam no que ele chamou de sistemas especialistas (expert systems, no original) em sua vida cotidiana, referindo-se à miríade de tecnologias com as quais interagimos diariamente sem realmente compreender como as mesmas funcionam; ele chega mesmo a descrever esta confiança em termos de fé, ainda que de um modo pragmático. Dada a complexidade da sociedade industrial moderna, isto significa que qualquer pessoa é leiga em mais áreas do que aquelas em que ele ou ela não é (Knorr-Cetina, 1999). Sistemas especialistas também existem na Medicina, e pelo menos alguns destes são tão inalcançáveis ao médico comum quanto aos leigos, embora os primeiros possam ter sido expostos a estes sistemas por meio da sua versão mais autoritarista, do tipo manual básico. Isto não significa que ao longo de sua carreira seu acesso a revistas técnicas e artigos de todo tipo será bloqueado, mas sim que eles podem carecer das habilidades necessárias para interpretar efetivamente o que é omitido e comprimido nestes artigos.

O conhecimento e a prática médicos se alimentam de uma variedade de fontes teóricas e técnicas, da mecânica quântica (a base dos métodos de imagem mais modernos) à biologia molecular, filtrando-os por meio de várias técnicas de avaliação e validação, que são parte de outra disciplina - a epidemiologia, que por sua vez se apóia pesadamente em ferramentas matemáticas - mais especificamente, estatísticas - no seu ofício. Nenhuma destas áreas do conhecimento é a província intelectual do médico praticante; nos termos de Fleck, os últimos são no máximo parte do círculo exotérico das mesmas.

O processo que transforma o estudante de Medicina num médico plenamente desenvolvido é uma inculcação organizada não apenas de certos conteúdos cognitivos, mas também de um modo distinto de definir o que a "realidade" é (Atkinson, 1997; Good, 1994). Este aprendizado é integrado num sistema de opiniões que, uma vez mais segundo Fleck (1979), resiste tenazmente aos desafios, criando o que ele definiu como "a harmonia das ilusões". Uma parte essencial deste estilo de pensamento é um conjunto de critérios que identifica o conhecimento confiável, usualmente definido como "verdadeiro", “objetivo" e "científico", de acordo com o que Good (1994) denominou a "epistemologia folk" da biomedicina. Com efeito, alegações de que a biomedicina é firmemente ancorada no conhecimento científico são generalizadas, como pode ser observado nos capítulos introdutórios de manuais clíni- cos (Barker et al., 1999; Isselbacher et al., 1994; Kassirer \& Kopelman, 1991).

Avaliar os critérios que os médicos usam na seleção de conhecimentos confiáveis coloca dois problemas em termos do trabalho original de Fleck. Em primeiro lugar, como já foi apontado neste texto, a prática médica não é usualmente orientada à produção de conhecimento. Isto significa que quaisquer que sejam os critérios usados pelos médicos, é menos provável que estes estejam expressos em textos escritos. Segundo, enquanto Fleck utilizou textos científicos como a base de sua análise, para entender como os médicos avaliam o conhecimento, o ponto de partida não pode ser os próprios textos, uma vez que o estilo de pensamento determina que textos são lidos, como eles são lidos, e como (ou se) eles são incorporados ao estoque de conhecimento disponível. Uma abordagem diferente é portanto necessária. Dada a descrição de Fleck de um estilo de pensamento como uma construção definida do pensamento, suas características deveriam também estar presentes em outras formas de produção discursiva, como a própria fala.

Em outras palavras, é necessário interagir e falar com pessoas que são parte daquele coletivo de pensamento. Como falar, e com que pessoas, são assuntos que serão abordados na descrição da metodologia do estudo.

\section{Métodos}

Esta pesquisa utiliza entrevistas e a observação etnográfica como ferramentas metodológicas para uma revisão em profundidade dos assuntos metodológicos e teóricos relacionados às técnicas de entrevista, ver Fontana \& Frey (2000) e Silverman (2000) -; este artigo apresenta os resultados de parte das entrevistas, enquanto o ramo etnográfico encontra-se em andamento.

Os informantes foram escolhidos dentre professores de escolas médicas, tendo em vista serem eles os responsáveis pela reprodução dos conhecimentos, práticas e valores da profissão. Adicionalmente, estes professores são quase invariavelmente profissionais respeitados também, ocupando portanto uma posição proeminente no campo médico. As escolas selecionadas são as duas mais tradicionais e respeitadas faculdades de Medicina do Rio de Janeiro. Os entrevistados foram escolhidos apenas entre os professores de clínica médica, uma vez que todos os alunos de Medicina são expostos a esta disciplina por períodos extensos ao longo de sua formação, ao contrário das 
especialidades médicas, que são usualmente abordadas em cursos curtos, determinando exposições mais curtas dos estudantes aos professores e tornando-os menos importantes, em termos gerais, no processo de moldagem da visão de mundo dos futuros médicos.

Para reduzir mais ainda o conjunto de entrevistas, apenas os professores mais respeitados em cada faculdade foram identificados, no primeiro passo propriamente empírico desta investigação. Na primeira escola, uma auxiliar de pesquisa, uma estudante de Medicina que participou durante esta etapa do projeto, conduziu várias entrevistas com os estudantes dos três últimos anos do curso médico (que tiveram contato com a maioria, senão todos, os professores de clínica médica) perguntando a estes simplesmente quais eram os melhores professores daquela disciplina em sua opinião.

Na segunda escola, o processo todo (entrevistas com estudantes e professores) foi conduzido por outra auxiliar de pesquisa, uma pesquisadora pós-graduada em saúde coletiva, sob minha supervisão. As entrevistas na segunda escola tiveram lugar após a conclusão da primeira série de entrevistas, e a auxiliar de pesquisa teve acesso às transcrições das mesmas antes de iniciar as conversas com professores, garantindo um padrão básico para todas as entrevistas.

Foram feitas vinte e quatro entrevistas no total, quatorze na primeira e dez na segunda escola. Em ambas, as entrevistas incluíram alguns médicos dos respectivos hospitais universitários que, embora não sejam professores no sentido estrito (não fazem parte dos corpos docentes das duas faculdades) são considerados desta forma pelos alunos, preenchendo portanto os requisitos dos critérios deste estudo e sendo por este motivo incluídos nas entrevistas.

Os entrevistados foram contatados nos hospitais universitários, e nestes contatos as entrevistas foram agendadas. Todas as entrevistas ocorreram em salas relativamente mais tranqüilas, próximas das enfermarias onde os entrevistados trabalham, durante algum espaço livre de sua escala, usualmente extremamente atarefada. Todas as entrevistas foram gravadas, com permissão dos entrevistados, e variaram entre trinta e cinco minutos a uma hora e quarenta minutos (aproximadamente). Tanto o contato inicial quanto a abertura das entrevistas foram padronizados; nós informávamos aos entrevistados que estávamos fazendo uma pesquisa sobre o ensino médico, e durante a entrevista fazíamos três perguntas padrão: qual era sua formação acadêmica; quais eram as características mais importantes de um médico; e como seria uma escola médica ideal. Estas perguntas não tinham qualquer relevância em si mesmas; pode-se dizer que as respostas diretas a elas eram em larga medida irrelevantes. Elas deveriam ser entendidas como meros dispositivos que auxiliaram a construção da narrativa compartilhada já mencionada neste texto. À medida que prosseguiam as entrevistas, por exemplo, nós perguntávamos como eles atualizavam seus conhecimentos, ou como eles peneiravam o material relevante em meio à massa de informações em que as revistas médicas - e mais recentemente a Internet - ameaçam soterrá-los. Se atividades de pesquisa não eram espontaneamente mencionadas, nós perguntávamos sobre seu envolvimento pessoal com a pesquisa e/ou a relevância que a mesma teria para a educação médica. Esta abordagem extremamente indireta foi escolhida de modo a minimizar o risco, sempre presente neste método de investigação, de induzir os entrevistado a responder o que eles julgam respostas “apropriadas", mesmo sem representar adequadamente suas visões.

As entrevistas resultantes foram transcritas e os arquivos de texto resultantes foram armazenados utilizando um programa gratuito denominado Logos, um sistema de bancos de dados textuais desenvolvido no Brasil especificamente como um auxílio à análise de dados não estruturados (Camargo Jr., 2000). Cada entrevista gerou um registro no arquivo, que foi analisado em busca da presença de temas recorrentes ligados ao conhecimento e prática médicos, bem como sua inter-relação. Blocos de texto foram codificados de acordo com a presença destes temas, e então selecionados e reagrupados de acordo com os mesmos.

\section{Resultados}

\section{Características dos entrevistados}

A comparação das características listadas nas duas escolas é apresentada na Tabela 1. Características individuais dos mesmos não são apresentadas, e seus nomes foram substituídos por pseudônimos de modo a preservar a privacidade dos entrevistados. Pelo mesmo motivo, as entrevistas das duas escolas são apresentadas sem referência à filiação institucional específica.

Não há diferenças importantes entre os dois grupos, e portanto, pelo restante deste texto toda a coleção de entrevistas será tratada como um corpo único, independentemente das instituições de onde se originaram. 
O processo de codificação - em si mesmo parte integral da análise (Ryan \& Bernard, 2000) - gerou seis temas recorrentes. Por razões de espaço, apenas um dos temas - conhecimento, o segundo mais freqüente nas entrevistas e sem dúvida o mais relevante para os objetivos deste estudo - será apresentado e analisado extensivamente neste artigo.

É importante mencionar, entretanto, que duas asserções feitas anteriormente neste texto foram reforçadas pelo material empírico relacionado às categorias que não serão apresentadas aqui:

- Estes médicos não são cientistas, eles não estão envolvidos com a produção de conhecimento de acordo com as práticas institucionais da ciência, e são consumidores de conhecimentos produzidos alhures. Poderia se argüir que isto deriva da escassez de recursos para a pesquisa no Brasil, se comparado com os países capitalistas centrais, mas os resultados preliminares de entrevistas realizadas com professores de Medicina canadenses, entretanto, indicam o contrário;

- A falta de distinção entre professores de Medicina e médicos do hospital universitário, assim como a menor importância atribuída aos títulos acadêmicos, ao menos na prática médica geral, são evidências importantes da inserção da educação médica como parte do campo médico mais geral.

\section{Apresentação detalhada} do tema "conhecimento"

Os fragmentos de texto estão agrupados em três subseções, representando momentos nas entrevistas que tiveram um padrão de desdobramento semelhante no tempo, como nas aberturas clássicas de xadrez. Uma vez mais por razões de espaço, as citações estão reduzidas ao mínimo possível.

\section{- Primeiro movimento: o trabalho médico nunca termina; o conhecimento nunca é suficiente}

Este tema é parte do senso comum médico: existe a necessidade de manter-se atualizado sobre os últimos desenvolvimentos do conhecimento médico, assumido como algo que cresce continuamente no tempo. Ao mesmo tempo, as outras demandas da profissão médica deixam pouco espaço para esta atividade. Esta dupla restrição é imediatamente evidente na seguinte citação: “(...) eu acho que, para um clí-
Tabela 1

Atributos por faculdade.

\begin{tabular}{lcc}
\hline Característica & Faculdade & Faculdade 2 \\
\hline Feminino & 3 & 2 \\
Masculino & 11 & 8 \\
Mestrado & 8 & 4 \\
Doutorado ou equivalente & 2 & 4 \\
Egressos da mesma faculdade & 10 & 8 \\
Graduado* & & \\
$\geq 30$ & 4 & 1 \\
$20-29$ & 4 & 4 \\
$10-19$ & 5 & 1 \\
$\leq 9$ & 1 & 0 \\
\hline
\end{tabular}

* Graduado refere-se ao intervalo (em anos) entre a graduação

a época da entrevista.

nico, se manter atualizado na medicina é muito difícil (...) É impossível, especialmente agora, com computadores, a Internet, com... uma difusão cada vez maior dos computadores... se manter atualizado" (Luís).

\section{- Segundo movimento: procurando agulhas em múltiplos palheiros - as estratégias de seleção}

Neste ponto da entrevista, costumávamos baixar nossa carta curinga: perguntar como selecionar ou triar a informação relevante/confiá$\mathrm{vel} /$ correta nas múltiplas fontes que constantemente os bombardeiam com elas. A forma exata como a pergunta era feita variou de acordo com o desenrolar da entrevista. Isto usualmente produziu as situações mais desconfortáveis na entrevistas; é interessante notar aqui também como as coisas eram ditas neste momento. Os entrevistados hesitavam, brigavam com as palavras, corriam em círculos, e às vezes não faziam nenhum sentido. Freqüentemente tivemos de refazer e recolocar a pergunta várias vezes antes de obter alguma informação utilizável, e ainda assim em alguns casos as respostas não foram exatamente informativas. Usualmente, desistimos de continuar perseguindo este assunto num certo ponto, por temor de induzir respostas por conta de uma pressão excessiva. $\mathrm{O}$ aspecto mais relevante dos trechos seguintes é que não há nenhum algoritmo geral neles. Escolhi o termo estratégias ao invés de critérios devido ao fato de que em todos os casos nenhum critério explícito era aparente, e seu procedimento era apresentado em termos de exemplos, ao invés de uma expo- 
sição metódica de conjuntos de regras. As estratégias efetivas variaram de indivíduo para indivíduo, e eram usualmente indefinidas e de difícil explicação. Preferências pessoais, conveniências, pedaços soltos de informação - como aqueles derivados de desenvolvimentos na Epidemiologia - pareceram todos desempenhar papéis variáveis nas estratégias compostas empregadas pelos entrevistados.

A necessidade de critérios de seleção foi apontada pela maior parte dos entrevistados, com ênfase particular no trecho seguinte: "Este é um dos maiores problemas que temos hoje em dia, a análise crítica do que nós temos (...) Você tem um monte de fontes, existem várias maneiras de se acessar a informação... (...) O problema é como separar o que é relevante do que não é" (Marcelo).

Luís apontou para uma mistura de interesse pessoal, relevância para a prática concreta, a autoridade relativa dos autores e uma vaga checagem de "métodos": "Ah, é muito difícil, é muito difícil, eu acho que... primeiro você pode tentar.. uma idéia, não é?... ver de onde está saindo esse artigo, esse trabalho... (...) [também deveria considerar] do método que eles utilizaram, do... da importância que aquilo tem...".

Ronaldo saiu-se com uma definição tautológica que curiosamente parece igualar "científico" a "estatístico"; "Bom, tem duas coisas: existem critérios científicos de como analisar um artigo médico e saber a relevância dele. Você lê um artigo e vê se ele tem um trabalho bem elaborado, se ele tem valor científico, se ele tem valor estatístico nos dados que ele mostra".

Jorge produziu, após muita insistência, uma descrição vaga de padrões, sem realmente elaborá-los. Ele também se refere a posições de autoridade, e o uso que faz do verbo "acreditar" é particularmente digno de nota: "Conhecimento científico é aquilo validado, no meu entender por critério... aceito pela comunidade científica. Então... dependendo do critério, também da base do trabalho... eu que acredito na medicina alopática, tenho uma formação nesse sentido... tem de partir de um trabalho randomizado, com critério, controlado, publicado em revista... [hesita] ter editorial, ter uma comissão julgadora decente... eu acho que é por aí... o trabalho científico é aquele que segue as normas universalmente aceitas pela ciência...".

De todos os entrevistados, Milton pareceu o mais desorientado por esta linha de questionamento, e referiu-se vagamente ao papel do senso comum como referência de medida, mas ao mesmo tempo assumindo que é um atributo ou propriedade de indivíduos, ao invés de uma habilidade aprendida: "[hesitante] Eu vejo essa lado muito pelo lado do bom senso na Medicina, que é o mais importante. Isso depende muito da pessoa que está exercendo, não sei se isso poderia ser ensinado...".

Joel aponta a influência das revistas especialmente com os clínicos mais jovens - e, conseqüentemente, mais inexperientes: “Isto é muito comum em médicos jovens, você vê isto nos residentes, eles surgem com um artigo da New England [New England Journal of Medicine] de ontem querendo tratar daquela forma [a doença], uma coisa que é claramente experimental ainda. Não é o consenso de diagnóstico ou de tratamento daquela doença, mas ontem saiu na New England isto, então... Isto é complicado, isto tem de ser ponderado, jovens médicos em geral têm tendência a acreditar, principalmente nestas revistas... Também se publicam bobagens nestas revistas".

Alexandre foi um dos poucos entrevistados a mencionar a existência de forças a que se deve resistir ao se adquirir conhecimento médico atualizado, embora mesmo ele não conseguisse ser particularmente preciso no que diz respeito a propor alternativas: "A pressão, a mídia, etc. ... se isto é uma coisa importante, ou não... (...) se alguém diz 'esse é o melhor antibiótico que tem... você tem de passar este antibiótico, ele cura tudo, está aqui a bacteriologia'... eu acho que o sujeito tem de ter uma coisa assim... a necessidade desse espírito crítico, de você não aceitar imediatamente... uma evidência, até qual é o seu conhecimento... (...) alguns periódicos que tentam filtrar alguma coisa, que também não são isentos de pressões... (...) acho que a epidemiologia clínica é uma arma que você precisa para fornecer dados ao paciente, ao médico para que ele tome determinadas decisões".

\section{- Terceiro movimento: as aparências enganam - ceticismo e desconfiança}

Na subseção anterior uma tendência comum de delegação pode ser vista nas citações - ao invés de critérios de validade, existe um reconhecimento a priori e implícito de certas fontes, principalmente institucionais, particularmente algumas revistas - o New England Journal of Medicine brilha intensamente como um símbolo consensual de autoridade cognitiva, sendo espontaneamente citado neste contexto por metade dos entrevistados, que se referem ao mesmo simplesmente como "o New England". Estes aspectos poderiam dar a entender que os entrevistados se satisfazem em desempenhar um papel passivo na aquisição de conhecimento. Não é o caso. O conjunto seguinte de citações mostra várias razões para 
que não se tome estas informações pelo seu valor de face, e restabelecendo uma vez mais o papel da experiência pessoal no processo.

Alberto faz uma crítica penetrante dos efeitos das políticas "publish or perish" (publicar ou perecer) na qualidade geral do que vem a ser publicado: “(...) o cara faz um trabalho sobre gases. Pô! E no final, o quê que o cara faz? OK, Gases. Tudo bem, vamos estudar gases. Mas o cara estuda gases sabe para o quê? Para aparecer. Ele tem de fazer um trabalho. Então, eles dizem assim: 'o doutor bom é o que publica'. Então se publica qualquer coisa... se publica qualquer besteira".

Célia toca num ponto semelhante, identificando razões adicionais para se olhar com cautela para os resultados de artigos: "[sobre novas drogas lançadas no mercado, irônica] Todos são ótimos, não é?... Ih, é bom... ah, perfeito, maravilha, e tal... Aí você quer ter a sua experiência, saber se realmente para a sua população, se aquele remédio foi bom...”.

Esta mesma entrevistada é ainda mais explícita noutro trecho na descrição do papel da indústria farmacêutica na conformação do conhecimento médico: "Você vai ouvir uma palestra em que ele diz que o melhor remédio para combater o colesterol alto é X... aí você olha, ele não comparou com nada, não é? E na verdade... porque que ele falou que era $\mathrm{o} X$ ? Porque ele fo $i$ financiado por um laboratório. Ou seja... isso porque sempre que... isso tem de estar escrito nas pesquisas, que você fez o estudo para o laboratório X, Y ou Z".

Pedro menciona o risco de se confiar em conhecimentos que são inerentemente instáveis: “... o que acontece é o seguinte: é o que estou falando, não adianta você ler muito, a verdade de hoje é a mentira de amanhã... (...) Quantas e quantas drogas você vê lançadas, no início como drogas milagrosas e que aí... que sumiram... alguns anos depois".

A maior parte dos entrevistados enfatizaram a importância da experiência pessoal no aprendizado da Medicina, e como um meio de desenvolver um "conhecimento de contraste", um padrão de comparação para a nova informação. Válter fez a afirmação mais explícita desta concepção: "Esta forma de você passar para os alunos que você não aprende simplesmente memorizando o livro de medicina, você aprende com a informação que o doente lhe dá e tirando desta informação o máximo que você puder. (...) É uma coisa de que cada doente é um ensinamento, não só do ponto de vista da doença orgânica, mas também como lidar com a cabeça das pessoas".

\section{Discussão dos achados}

O primeiro ponto a ser abordado é o da sobrecarga informacional percebida - o que eu chamaria de Efeito Sísifo. A falta de tempo livre dos médicos, ao menos neste grupo, é um fato incontestável assim como o é o volume expressivo de novas publicações continuamente despejadas por um número crescente de revistas. Mas o que poderia parecer um próximo passo lógico, a noção de senso comum de que o conhecimento médico cresce a uma velocidade alucinante, fazendo com que tudo mude quase da noite para o dia, deve ser cuidadosamente considerada.

Retornando às citações que abrem este artigo, podemos encontrar idéias implícitas sobre o contínuo "progresso da ciência" e de "avanços médicos" que poderiam ser criticados em vários aspectos, mas mesmo tomandoos como dados, quão "freqüentes" e "significativas" as mudanças que eles trazem realmente são? É interessante notar que nenhuma demonstração deste fenômeno é dada, como se ele fosse auto-evidente. Um estudo sobre a inovação em Medicina está completamente fora do escopo deste texto (um exemplo deste tipo de estudo, uma análise extensa da inovação em técnicas de imagem, pode ser encontrado em Blume (1992), mas pelo menos algumas observações se impõem).

O grosso das inovações tanto em termos de equipamentos médicos quanto de remédios origina-se atualmente no setor privado. Isto significa que forças econômicas têm um papel fundamental nesta dinâmica, e deveriam ser levadas em consideração ao analisar tais mudanças na Medicina. Curiosamente, os anais de uma conferência promovida pela Academia de Ciências de Nova York sobre a avaliação das intervenções no cuidado em saúde (Mosteller \& Warren, 1993), que tinha os mais importantes proponentes da MBE como palestrantes principais, logrou manter-se completamente afastada deste fato algo óbvio.

Estes mercados têm um número limitado de fabricantes, companhias de alta tecnologia que são parte de grandes corporações transnacionais. Analisando as inovações em Medicina deste ângulo, mudanças "freqüentes" e "significativas" parecem menos prováveis. Produtos têm um ciclo de vida, e introduzir produtos (ou linhas inteiras) nas mesmas categorias antes que os anteriores tenham realizado plenamente seu potencial econômico constitui-se num cenário improvável. Um fluxo permanente de inovações, que são freqüentes ou significativas, mas raramente, ou nunca, ambas, faz mais sen- 
tido em termos econômicos. Reforçar a idéia de que elas de fato ocorrem numa tal velocidade de tirar o fôlego, entretanto, pode ser uma estratégia de marketing extremamente efetiva. Este é um ponto que vai ser abordado em maior detalhe mais adiante nesta mesma seção; por ora, contudo, o que deve ser enfatizado é termos ao menos algumas razões para encarar alegações sobre revoluções contínuas na Medicina com algum ceticismo.

O próximo elemento a ser analisado é a estratégia seletiva, ou estratégias, empregada(s) pelos médicos entrevistados. Primeiro, existe um aspecto interessante no modo pelo qual elas vieram à tona nas entrevistas. Considerando que estávamos discutindo uma operação corriqueira de suas vidas cotidianas, o fato de que eles tiveram dificuldades em explicá-la é particularmente intrigante. Existe aqui uma analogia digna de nota com a descrição de estratégias diagnósticas apresentadas por Sackett et al. (1991), especialmente a que eles denominam reconhecimento de padrões. De acordo com estes autores, um componente chave do diagnóstico médico é o reconhecimento imediato de agregados de sinais, apreendidos como uma totalidade gestáltica, e não analiticamente, um por um. O aspecto interessante é que estes autores dizem que embora uma reconstituição post-facto de um procedimento passo-a-passo possa ser oferecida pelos médicos, não é de fato o que ocorre. O mecanismo efetivo de reconhecimento de padrões ocorre demasiado rápido para isto. Pode-se portanto hipotetisar que os médicos empreguem estratégias similares para selecionar informações ao buscarem sua atualização às que empregam ao diagnosticar, rapidamente selecionando certos elementos e reconstruindo-os numa gestalt. A dificuldade por eles experimentada na explicação de tais procedimentos derivaria então do fato de não estarem seguindo um fluxograma quando executando suas estratégias, mas operando num nível muito mais intuitivo. Esta observação também agrega plausibilidade à hipótese de que os médicos não são plenamente capacitados a avaliar artigos de revistas científicas - se este fosse o caso, procedimentos mais definidos, plenamente conscientes e sistemáticos seriam esperáveis.

É também possível derivar uma hierarquia de fontes de conhecimento das entrevistas. No nível do topo, como fonte mais importante, está a experiência pessoal. Isto significa o aprendizado à beira do leito para os estudantes; para os médicos, é não apenas a experiência profissional direta, vivida, mas também a aquisição por proximidade, o aprendizado derivado da interação contínua com colegas e mesmo alunos. No segundo nível está a informação textual. Existem três subcategorias neste nível: artigos de revista, manuais de referência e a Internet. A Internet é a fonte mais dinâmica e conveniente, embora não necessariamente a mais confiável, enquanto livros são vistos como inerentemente desatualizados, mas também sólidos como rochas quando se trata de conhecimento comprovado; os artigos ocupam uma posição intermediária. Estes achados são fortemente similares à descrição de Fleck sobre as variedades de comunicação científica, já citada no início deste artigo, com duas importantes exceções: a primeira é obviamente a Internet, que não existia à sua época; a segunda $\mathrm{e}$ mais intrigante, contudo, é a falta de referência aos manuais básicos. Uma explicação possível para isto é que não há na verdade uma distinção clara entre livros de referência e manuais básicos na Medicina Clínica, embora possa ser o caso em áreas específicas, como por exemplo a semiologia - existem de fato vários textos introdutórios ao método clínico.

Embora exista consenso sobre as características de cada uma destas formas textuais entre os entrevistados, a posição relativa destes dentro desta categoria varia consideravelmente de acordo com o entrevistado. Alguns dos médicos mais jovens tendem a confiar mais na Internet do que os mais velhos, por exemplo, mas esta não é uma regra geral; um dos maiores entusiastas da Internet é Renato, que está no grupo de meia idade (em relação aos entrevistados) e Alberto, um dos mais velhos, embora não tão entusiasta é menos crítico que Luiza, por exemplo. Algumas expressões recorrentes também apontam para a existência de gradientes mesmo dentro de uma mesma subcategoria, como por exemplo, "notas de rodapé" nos livros de referência e "o último artigo" (freqüentemente, "o último artigo do New England"), sinônimos de conhecimento supérfluo, no primeiro caso, e instável e arriscado, no segundo. Ambos estão associados ao médico "traça" ou "rato de biblioteca", mais preocupado com a teoria do que com a prática, um estereótipo com o qual nenhum deles quer ser associado. Tanto este estereótipo quanto a sua repulsividade são também fortes evidências da primazia epistemológica da experiência para eles. Ainda com respeito a isso, uma abordagem claramente pragmática, orientada a resultados, é empregada em suas estratégias, às vezes ao ponto de dispensar completamente a leitura das metodologias empregadas nos estudos. Da mesma forma, a informação sobre as chamadas "ciências básicas" não foi nunca 
considerada importante nas entrevistas. Eles efetivamente confiam, contudo, em marcadores institucionais de autoridade epistêmica como critério seletivo; livros estrangeiros na sua linguagem original são mais respeitados que as versões localmente produzidas ou traduzidas. Deve ser notado a este respeito a absoluta dominância de publicações na língua inglesa como referência para os médicos entrevistados, tanto em termos de revistas quanto de livros de referência. Esta dominância é tão acachapante que muitos dos autores utilizaram uma expressão para se referir aos livros de referência - "livro-texto" - que é uma tradução literal, mas sem sentido para o português, da palavra correspondente em inglês, "textbook". Em termos de revistas, como já foi apontado, o New England Journal of Medicine é unanimemente reconhecido como símbolo de excelência. Curiosamente, Christakis et al. (2000) alegam que este viés não foi observado num estudo por eles conduzido, ainda que a situação artificial criada em seu experimento (artigos de duas revistas - uma delas, não por coincidência, sendo o New England Journal of Medicine - foram dados aos participantes da pesquisa, com sua origem sendo informada em alguns casos e não em outros, e foi pedido que os mesmos fossem avaliados) fosse completamente diferente do que se dá na prática concreta. Após discutir as limitações presentes no seu desenho, eles concluem o artigo com as seguintes observações: “Estas limitações nos proíbem de concluir que um viés de atribuição por revista não ocorra. Não obstante, nossos resultados são encorajadores. Eles sugerem que tendo o tempo e a dedicação necessária à revisão de um artigo ou resumo cuidadosamente, médicos - independentemente de seu treino formal em epidemiologia ou bioestatística - são capazes de ler artigos sem um viés significante ou discernivelmente grande baseado na fonte de publicação" (Christakis et al., 2000:777). O problema está precisamente no fato de que os médicos não dispõem do tempo necessário para rever criticamente tudo, e a seleção de artigos baseada nas fontes ocorre antes que os médicos os leiam. Finalmente, no degrau mais baixo estão as comunicações orais passivas: congressos, simpósios, palestras e encontros patrocinados pela indústria farmacêutica no lançamento de novas drogas (mais sobre este ponto, adiante). Estes são passivos do ponto de vista dos entrevistados, e não deveriam ser confundidos com o aprendizado por proximidade, que é o resultado de uma interação interpessoal sistemática, estreitamente articulada com a prática profissional. Embora houvesse divergência na apreciação deste tipo de atividade - Marcos, Célia e Luiza explicitamente a descartam, enquanto Selma e Luís a consideram um método legítimo de receber informação "mastigada”, de modo fácil, por exemplo - mesmo os que ainda a consideram útil, colocam a mesma no nível mais baixo. Cursos de treinamento foram mencionados ocasionalmente, mas basicamente como uma impossibilidade devido às suas vidas ocupadas. Existe uma superposição considerável desta hierarquia com os achados de Fernandez et al. (2000), que apontaram fontes similares de conhecimento na Medicina.

O último ponto a ser abordado nesta seção é o ceticismo identificado nas entrevistas. $\mathrm{O}$ ceticismo médico não tem nada de novo; com efeito, a expressão ceticismo terapêutico é utilizada como rótulo para identificar um período na história da Medicina (fim do século XIX), onde a maior parte da infra-estrutura teórica da moderna Medicina estava disponível, embora ainda sem dispor das correspondentes opções terapêuticas (Sayd, 1998). Os médicos eram então, como agora, céticos sobre sua farmacopéia, mas não tinham escolha a não ser utilizá-la, então e agora. Embora talvez os médicos hoje em dia tenham mais motivos de confiança que seus colegas do século XIX, eles similarmente não dispõem de alternativas que os habilitem a levar seu ceticismo às últimas conseqüências. Retornando ao argumento econômico anteriormente apresentado, deve se notar que a produção de conhecimento médico, ou melhor dizendo, de conhecimento com potenciais usos médicos é também parte da mesma dinâmica econômica. Uma vez que a pesquisa é produzida principalmente por empresas privadas com enormes interesses econômicos em jogo, existe uma concentração desproporcional de poder em um lado deste negócio. As companhias produzem o conhecimento, financiam por meio de anúncios as principais revistas (por sua vez também editadas por grandes companhias editoras que são, num certo sentido, parte do mesmo setor da economia - e o mesmo poderia ser dito da maioria dos livros de referência), financiam simpósios e congressos médicos e até mesmo pagam a médicos individualmente para que estes vão a estes eventos. Companhias farmacêuticas patrocinam encontros para lançar novos remédios, que partilham uma curiosa $m i$ se-en-scène comum: um especialista de renome é convidado a apresentar o novo produto, usualmente em um ambiente luxuoso como um hotel de primeira linha; durante a apresentação, a autoridade convidada nunca se refere ao remédio pelo seu nome comercial, mas ape- 
nas pelo da substância farmacologicamente ativa, embora o local esteja literalmente coberto por cartazes e faixas exibindo o nome do produto e da empresa com grande destaque. Finalmente, a estratégia mais empregada envolve a utilização de exércitos de agentes de marketing da indústria farmacêutica, que enxameiam em torno de hospitais e clínicas, distribuindo amostras grátis e vários brindes, práticas que se demonstrou afetar os padrões de prescrição dos clínicos (Wazana, 2000). Tais efeitos são também notados por DiNubile (2000).

Uma tal gama de forças irá inevitavelmente introduzir vieses importantes no conhecimento e prática médicos (Friedberg et al., 1999; Krimsky, 1999; Stelfox et al., 1998; Stern \& Simes, 1997). Enquanto o já citado DiNubile (2000) deplora esta situação como um resultado de um insuficiente ceticismo dos médicos, este não parece, contudo, ser o caso. A postura cética dos entrevistados foi claramente evidente e bem argumentada. Quase todos os entrevistados forneceram exemplos - evidência anedotal convincente - de casos onde diretrizes não foram estritamente seguidas e o sucesso terapêutico foi ainda assim alcançado, e inversamente de situações onde houve adesão estrita a protocolos sem sucesso. Não obstante, os médicos carecem de recursos para usar plenamente seu ceticismo para enfrentar as forças maciças da indústria do conhecimento médico. Isto não é muito diferente da situação do dissidente hipotético descrita por Latour (1987), que persiste em desafiar as alegações dos cientistas, até ser finalmente silenciado pela atordoante constelação de recursos que os últimos podem mobilizar em seu apoio. Não importa quão cético, no final o médico não tem escolha a não ser desistir.

A natureza exploratória deste estudo foi apontada no início deste artigo. Pesquisas adicionais serão necessárias para que as conclusões que se seguem possam ser amplamente extrapoladas; com efeito, outro conjunto de entrevistas, feitas com professores canadenses, ainda está sendo analisado, e o ramo etnográfico do estudo está em andamento. Outro estudo, ligado a este mas abordando especificamente a área de Cardiologia, também está sendo realizado. De qualquer modo, esta é uma área que, como já foi dito no início deste texto, demanda mais atenção do que o que tem recebido até o momento.

\section{Conclusões: conseqüências de um estilo de pensamento particular}

O modo de pensar que emerge deste conjunto de entrevistas pode ser caracterizado resumidamente como uma busca amplamente intuitiva, pragmática, orientada a resultados, por informação relevante (isto é, potencialmente útil na prática), selecionada de fontes com suficiente credibilidade acadêmica e submetida a um primado do conhecimento prático, experiencial, com uma atitude bastante cética, às vezes bordejando o cinismo. Apesar deste ceticismo, entretanto, os médicos carecem de recursos (isto é, tempo, conhecimento de aspectos técnicos da pesquisa, particularmente em termos de epidemiologia e estatística) para avaliar o conhecimento que lhes está continuamente sendo impingido. Esta falta relativa de recursos é piorada por um lado pela percepção da Medicina como sujeita a mudanças significativas e freqüentes, e por outro pelas forças vastamente desproporcionais disponíveis para os que efetivamente produzem e distribuem tal conhecimento.

A descrição apresentada acima tem alguns paralelos com a caracterização feita por Freidson (1972), daquilo que denomina de "mentalidade clínica", mas distinguindo-se entretanto em pelo menos dois aspectos fundamentais: primeiro, Freidson preocupa-se em descrever o pensamento dos médicos de um modo geral, ignorando por completo o aspecto que é o eixo central deste estudo, as estratégias que estes empregam na seleção de conhecimento confiável dentre uma variedade de fontes; segundo, enquanto Freidson (1972:170), declara simplesmente que “(...) o praticante passa essencialmente a confiar na autoridade de seus próprios sentidos, independentemente da autoridade geral da tradição ou ciência", as preocupações externadas pelos entrevistados em estar permanentemente atualizados, refletindo um tema recorrente também na literatura médica, comprometem tal afirmação.

O efeito líquido deste modo de pensar é a receptividade da profissão médica às informações pré-digeridas e pré-selecionadas apresentadas pelo lado industrial do complexo médico-industrial. Rampton \& Stauber (2000), apresentam exemplos onde certas companhias conseguiram contratar cientistas para produzir (ou, nos piores casos, apenas assinar) artigos refletindo seus interesses que foram publicados em revistas de prestígio, até mesmo o New England Journal of Medicine, ou ainda como o financiamento enviesa os protocolos de pesquisa e, conseqüentemente, seus resultados. A 
busca dos médicos por conhecimento atualizado até o último minuto, uma das características de seu estilo de pensamento, é reconhecida e utilizada pela indústria do conhecimento médico em favor dela própria. As soluções propostas atualmente, como a adoção de estratégias com base na chamada MBE têm entre outros problemas a falha em reconhecer as extensas raízes sociais, econômicas e mesmo políticas dos dilemas encarados pelos médicos. Adicionalmente, o fato de se apoiarem numa abordagem do tipo "receita de bolo" da estatística compromete a confiança dos médicos em suas próprias formas específicas de conhecimento, derivadas de um método clínico que enfatiza casos individuais, e reforça mais ainda sua sujeição epistêmica a uma disciplina que não é

\section{Agradecimentos}

A realização deste trabalho foi possível graças a financiamentos concedidos pelo Conselho Nacional de Desenvolvimento Científico e Tecnológico (CNPq), Coordenação de Aperfeiçoamento de Pessoal de Nível Superior (CAPES) e pela Universidade do Estado do Rio de Janeiro (UERJ). usualmente plenamente apreendida por eles. Como Isaac Asimov (1991:5) escreveu no seu livro de ficção científica, Prelude to Foundation, "não se acreditaria igualmente em todas as pessoas (...) Um matemático, entretanto, que poderia sustentar sua profecia com fórmulas e terminologia matemáticas, poderia não ser entendido por ninguém e ainda assim ter todos acreditando nele".

O saudável ceticismo dos médicos necessita de recursos para poder enfrentar as forças a que se opõe. A produção e difusão do conhecimento médico são portanto também problemas de saúde coletiva, e como tal deveriam ser abordados por políticas públicas, e mais fortemente financiados com recursos públicos, particularmente no último aspecto.

\section{Referências}

ASIMOV, I., 1991. Prelude to Foundation. New York: Bantam Books.

ATKINSON, P., 1997. The Clinical Experience: The Construction and Reconstruction of Medical Reality. Aldershot: Ashgate Publishing.

BARKER, L. R.; BURTON, J. R. \& ZIEVE, P. D. (ed.), 1999. Principles of Ambulatory Medicine. $5^{\text {th }} \mathrm{Ed}$. Baltimore: Williams \& Wilkins.

BATES, D. G., 2000. Why not call modern medicine "alternative"? Perspectives in Biology and Medicine, 43:502-518.

BLUME, S. S., 1992. Insight and Industry: On the Dynamics of Technology Change in Medicine. Cambridge: MIT Press.

CAMARGO Jr., K. R., 2000. Apresentando Logos: Um gerenciador de dados textuais. Cadernos de Saúde Pública, 16:286-287.

CANGUILHEM, G., 1978. On the Normal and the Pathological. Dordrecht: D. Reidel.

COHEN, R. S. \& SCHNELLE, T. (ed.), 1986. Cognition and Fact-Materials on Ludwik Fleck. Dordrecht: D. Reidel.

CHRISTAKIS, D. A.; SAINT, S.; SAHA, S.; ELMORE, J. G.; WELSH, D. E.; BAKER, P. \& KOEPSELL, T. D., 2000. Do physicians judge a study by its cover? An investigation of journal attribution bias. Journal of Clinical Epidemiology, 53:773-778.

DiNUBILE, M. J., 2000. Skepticism: A lost clinical art. Clinical Infectious Diseases, 31:513-518. 
FERNANDEZ, L. A. L.; MARTIN, J. M. J.; DEL CASTILLO, J. D. L.; GASPAR, O. S.; MILLAN, J. I.; LOZANO, M. J. \& KEENOY, E. D., 2000. Sources of influence on medical practice. Journal of Epidemiology and Community Health, 54:623-630.

FLECK, L., 1979. Genesis and Development of a Scientific Fact. Chicago: University of Chicago Press.

FLECK, L., 1986. Some specific features of the medical way of thinking. In: Cognition and Fact-Materials on Ludwik Fleck (R. S. Cohen \& T. Schnelle, ed.), pp. 39-46, Dordrecht: D. Reidel.

FONTANA, A. \& FREY, J. H., 2000. The interview: From structured questions to negotiated text. In: Handbook of Qualitative Research (N. K. Denzim \& Y. S. Lincoln, ed.), pp. 645-672, 2nd Ed., Thousand Oaks: Sage Publications.

FREIDSON, E., 1972. Profession of Medicine: A Study of the Sociology of Applied Knowledge. New York: Dodd, Mead \& Co.

FRIEDBERG, M.; SAFFRAN, B.; STINSON, T. J.; NELSON, W. \& BENNETT, C. L., 1999. Evaluation of conflict of interest in economic analyses of new drugs used in oncology. JAMA, 282:1453-1455.

GIDDENS, A., 1990. The Consequences of Modernity. London: Polity Press/Basil Blackwell.

GOOD, B. J., 1994. Medicine, Rationality and Experience. Cambridge: Cambridge University Press.

HACKING, I., 1999. The Social Construction of What? Cambridge: Harvard University Press.

ISSELBACHER, K. J.; MARTIN, J. B.; FAUCI, A. \& BRAUNWALD, E. (ed.), 1994. Harrison's Principles of Internal Medicine. 13th Ed. New York: McGrawHill.

KASSIRER, J. P. \& KOPELMAN, R. I., 1991. Learning Clinical Reasoning. Baltimore: Williams \& Wilkins.

KNORR-CETINA, K., 1999. Epistemic Cultures. Cambridge: Harvard University Press.

KRIMSKY, S., 1999. Conflict of interest and cost-effectiveness analysis. JAMA, 282:1474-1475.

KUHN, T. S., 1979. Foreword. In: Genesis and Development of a Scientific Fact (L. Fleck, ed.), pp. vixi, Chicago: University of Chicago Press.

KUHN, T. S., 1996. The Structure of Scientific Revolutions. $3^{\text {rd }}$ Ed. Chicago: University of Chicago Press.

LATOUR, B., 1987. Science in Action: How to Follow Scientists an Engineers Through Society. Cambridge: Harvard University Press.
LUZ, M. T. \& CAMARGO Jr., K. R., 1997. A comparative study of medical rationalities. Curare - Journal of Ethnomedicine, 12:47-58.

RAMPTON, S. \& STAUBER, J., 2000. Trust Us, We're Experts!: How Industry Manipulates Science and Gambles with Your Future. New York: Jeremy P. Tarcher/Putnam.

RYAN, G. W. \& BERNARD, H. R., 2000. Data management and analysis methods. In: Handbook of Qualitative Research (N. K. Denzim \& Y. S. Lincoln, ed.), pp. 769-802, 2nd Ed., Thousand Oaks: Sage Publications.

SACKETT, D. L.; HAYNES, R. B.; GUYATT, G. H. \& TUGWELL, P., 1991. Clinical Epidemiology. 2nd Ed. Boston: Little, Brown \& Co.

SACKETT, D. L.; RICHARDSON, W. S.; ROSENBERG, W. \& HAYNES, R. B., 1997. Evidence-Based Medicine: How to Practice \& Teach EBM. Edinburgh: Churchill Livingstone.

SAYD, J. D., 1998. Mediar, Medicar, Remediar: Aspectos da Terapêutica na Medicina Ocidental. Rio de Janeiro: Eduerj.

SILVERMAN, D., 2000. Analyzing talk and text. In: Handbook of Qualitative Research (N. K. Denzim \&Y. S. Lincoln, ed.), pp. 821-834, 2nd Ed., Thousand Oaks: Sage Publications.

STELFOX, H. T.; CHUA, G.; O'ROURKE, K. \& DETSKY, A. S., 1998. Conflict of interest in the debate over calcium-channel antagonists. New England Journal of Medicine, 338:101-106.

STERN, J. M. \& SIMES, R. J., 1997. Publication bias: Evidence of delayed publication in a cohort study of clinical research projects. BMJ, 315:640-645.

WARREN, K. S. \& MOSTELLER, F. (ed.), 1993. Doing more good than harm: The evaluation of health care interventions. Annals of the New York Academy of Sciences 703. New York: New York Academy of Sciences.

WAZANA, A., 2000. Physicians and the pharmaceutical industry - Is a gift ever just a gift? JAMA, 283:373-380.

Recebido em 20 de março de 2002

Versão final reapresentada em 17 de fevereiro de 2003 Aprovado em 30 de abril de 2003 